\title{
TWO FIBULAE FROM "EARLY-SARMATIAN" BURIALS OF THE NORTH-WESTERN BLACK SEA REGION
}

\author{
Viktor V. Kropotov \\ Institute of Archaeology of the Crimea (RAS), Simferopol, Russian Federation
}

\begin{abstract}
The article analyzes the metal fibulae found in 2 burials: the first one in the burial No. 4 from the Kholmskoe cemetery and the second one in the burial No.7 from the kurgan No. 1 near to the Nikolskoe village. These burials appear in most of the generalizing works as the most ancient Sarmatian monuments of the NorthWestern Black Sea Region, although their exact date is still debatable. Furthermore, the researchers date the complex from the burial Kholmskoe to the different time periods such as: the beginning / first half / the end of the $1^{\text {st }}$ century BC, or even later time. While the burial near to the Nikolskoe village is dated by various time intervals from the second half of the $3^{\text {rd }}$ century $\mathrm{BC}$ to the middle of the $2^{\text {nd }}$ century BC. Acquaintance with the original fibula from the burial No. 4 of the Kholmskoe cemetery, stored in the Odessa Archaeological Museum of the National Academy of Sciences of Ukraine, has allowed the author to identify this sample with the latest form of fibula of the Early La Tene scheme, which existed in the $2^{\text {nd }}$ century BC, possibly in the second half of this century. Additionally, the fibula from the burial No.7 of the kurgan close to the Nikolskoye village should be dated within the $2^{\text {nd }}$ century BC, since it belongs to the "dismembered" fibulae of the Middle La Tene scheme. It is important to highlight that both items, regardless of their narrow dating, are undoubtedly more ancient artifacts compared to the majority of fibulae of the Northern Black Sea region, marking the earliest Sarmatian monuments in the region. Sarmatian antiquities, which are synchronous to the mentioned particular artifacts are inherent only to the Volga-Don steppes and further to the east. In this regard, it is more relevant to correlate the studied complexes under consideration with the simultaneous and territorially close monuments of the Tiraspol group, reasonably associated with the Late Scythian culture.
\end{abstract}

Key words: North-Western Black Sea Region, cemetery, kurgan, barrow, fibula, Late Scythians, Sarmatians, Hellenistic period.

Citation. Kropotov V.V., 2020. Dve fibuly iz «rannesarmatskih» pogrebeniy Severno-Zapadnogo Prichernomor'ya [Two Fibulae from "Early-Sarmatian" Burials of the North-Western Black Sea Region]. Nizhnevolzhskiy Arkheologicheskiy Vestnik [The Lower Volga Archaeological Bulletin], vol. 19, no. 2, pp. 153-163. DOI: https://doi.org/10.15688/nav.jvolsu.2020.2.8

УДК 903'1(47+57):687.078

Дата поступления статьи: 08.09.2020

ББК 63.442.1(2)-41

Дата принятия статьи: 24.11.2020

\section{ДВЕ ФИБУЛЫ ИЗ «РАННЕСАРМАТСКИХ» ПОГРЕБЕНИЙ СЕВЕРО-ЗАПАДНОГО ПРИЧЕРНОМОРЬЯ}

\author{
Виктор Валерьевич Кропотов \\ Институт археологии Крыма РАН, г. Симферополь, Российская Федерация
}

Аннотация. В статье анализируются металлические застежки-фибулы из погребения 4 грунтового могильника Холмское и погребения 7 из кургана 1 у с. Никольское. Эти захоронения фигурируют в большинстве обобщающих работ в качестве наиболее древних сарматских памятников Северо-Западного Причерноморья, хотя их точная датировка до сих пор остается дискуссионной. Так, комплекс из Холмского исследователи относят то к началу / первой половине I в. до н.э., то к концу этого столетия, то к еще более позднему времени, а погребение из Никольского датируют различными временными промежутками от второй половины III в. до н.э. до середины II в. до н.э. Ознакомление с оригиналом фибулы из погребения 4 могильника Холмское, хранящимся в Одесском археологическом музее НАН Украины, позволило автору отождествить 
данный образец с наиболее поздней формой фибул раннелатенской схемы, бытовавшей во II в. до н.э., возможно - второй половине этого столетия. Также в пределах II в. до н.э., по-видимому, следует датировать и фибулу из погребения 7 кургана 1 у с. Никольское, относящуюся к «расчлененным» застежкам среднелатенской схемы. Важно подчеркнуть, что оба изделия, независимо от их узкой датировки, несомненно являются более древними артефактами по сравнению с основным массивом фибул Северного Причерноморья, маркирующих самые ранние сарматские памятники региона. Синхронные им древности сарматов известны только в волго-донских степях и далее к востоку. В этой связи рассматриваемые комплексы логичнее соотнести с одновременными и территориально близкими им памятниками Тираспольской группы, обоснованно связываемыми с позднескифской культурой.

Ключевые слова: Северо-Западное Причерноморье, могильник, курган, погребение, фибула, поздние скифы, сарматы, эллинистический период.

Цитирование. Кропотов В. В., 2020. Две фибулы из «раннесарматских» погребений Северо-Западного Причерноморья // Нижневолжский археологический вестник. T. 19, № 2. C. 153-163. DOI: https://doi.org/ 10.15688/nav.jvolsu.2020.2.8

Среди погребальных памятников $\mathrm{Ce}$ верного Причерноморья, традиционно связываемых с раннесарматской культурой, особого внимания заслуживают два комплекса, расположенные в западной части региона на значительном удалении от других раннесарматских захоронений и отличающиеся от них рядом индивидуальных особенностей. Это погребение 4 из грунтового могильника у с. Холмское, открытое вблизи дельты р. Дунай [Гудкова, Фокеев, 1984, c. 8-10], и погребение 7 в кургане 1 у с. Никольское на левобережье р. Днестр [Levinschi, Agulnicov, 1998, р. 87; Агульников, Сава, 2004, c. 11-12].

Первое из них совершено в могиле с «заплечиками» головой на юго-запад и, возможно, первоначально было перекрыто невысокой курганной насыпью, полностью распаханной до начала раскопок. Усопшую (ее возраст не определен) сопровождал достаточно многочисленный инвентарь, состоящий из гончарного красноглиняного кувшина, двух серебряных двухвитковых проволочных браслетов с концами, украшенными в виде змеиных головок, двух проволочных полуторавитковых браслетов с гладкими концами, серебряной фибулы, золотых умбоновидных бляшек, железных ведерковидных подвесок, разнообразных бус и пр. (рис. 1).

Второе погребение находилось в насыпи кургана эпохи энеолита на небольшой глубине, контуры вмещавшего его погребального сооружения проследить не удалось. При покойном (ребенке 4-6 лет), ориентированном головой на юг, обнаружены только лепной сосуд и бронзовая фибула (рис. 3).
Оба памятника играют большую роль в определении времени проникновения сарматов в Северо-Западное Причерноморье и в этноисторической реконструкции связанных с этим событий. Вместе с тем точная датировка захоронений до сих пор остается дискуссионной, а их интерпретация в качестве древностей сарматского круга - во многом интуитивной.

Важно отметить, что в указанных комплексах были найдены металлические застежки-фибулы, являющиеся общепризнанными точными и надежными хронологическими индикаторами. Настоящее сообщение посвящено их типолого-хронологическому анализу с целью уточнения датировки данных захоронений.

Обе фибулы опубликованы и достаточно подробно описаны [Гудкова, Фокеев, 1984, c. 8,23 , рис. 2,11; Levinschi, Agulnicov, 1998, p. 87-89, fig. 1,2].

Фибулу из погребения 4 грунтового могильника у с. Холмское, сохранившуюся лишь фрагментарно, авторы раскопок памятника А.В. Гудкова и М.М. Фокеев идентифицировали как застежку среднелатенской схемы со свободным концом ножки, скрепленным со спинкой с помощью скрепы-муфты, и датировали I в. до н.э. [Гудкова, Фокеев, 1984, c. 8, 23]. Предложенное ими типологическое определение стало общепринятым (см., например: [Щукин, 1989а, с. 35, 37; Гросу, 1990, c. 41; Дзиговський, 1993, с. 55]). Именно как гладкая скрепленная фибула среднелатенской схемы застежка вошла в свод фибул юга Восточной Европы сарматского времени, подготовленный автором [Кропотов, 2010, 
c. 44-45]. Дискуссия развернулась лишь по поводу датировки всего комплекса в целом его предлагали относить либо к началу / первой половине I в. до н.э. [Симоненко, 1994, с. 35, 45; Дзиговский, 2003, с. 69], либо к концу этого столетия [Щукин, 1989а, с. 37; 1989б, c. 70; Гросу, 1990, с. 41; Дзиговський, 1993, c. 71], либо даже к еще более позднему времени [Кропотов, 2001, с. 187; Сергацков, 2007, c. 410].

Ознакомление с оригиналом, хранящимся в Одесском археологическом музее НАН Украины, позволило иначе интерпретировать этот предмет.

Как уже было указано выше, фибула представлена не полностью. В фондах ОАМ (№ 54620) хранится только ее корпус с симметричной восьмивитковой пружиной, намотанной на бронзовую ось; тетива верхняя. Прямая прямоугольная в сечении спинка изделия резко изогнута перед пружиной и несколько нависает над ней. Плавно сужающийся корпус переходит в ножку, сгибаясь под прямым углом. На корпусе частично сохранилась припаянная к нему дополнительная пластина, полностью повторяющая его по форме. Ножка, приемник и игла фибулы утрачены. Длина сохранившегося фрагмента 5,9 см, высота 2,2 см, максимальная ширина корпуса 0,5 см (рис. 2,1-4).

Первое, что следует отметить при анализе описываемого экземпляра, - это форма спинки, не типичная для гладких скрепленных фибул среднелатенской схемы, к которым принято относить данный образец. Она прямоугольная в сечении, а не круглая проволочная, как у всех фибул указанной группы. Вместе с тем аналогичные уплощенные спинки-дужки хорошо известны у фибул раннелатенской схемы и некоторых форм среднелатенских «расчлененных», широко бытовавших в предшествующее время (см., например: [Кропотов, 2010, рис. 17,1-3, 23,4]).

Вторая важная особенность данного изделия - отсутствие на корпусе каких-либо следов скрепы или муфты, с помощью которой к спинке мог быть прикреплен свободный конец ножки. А.В. Гудкова и М.М. Фокеев, скорее всего, указали на ее наличие лишь гипотетически, основываясь на интерпретации накладной пластины на корпусе как свобод- ного конца ножки, скрепленного со спинкой с ее помощью.

К сожалению, ни ножка, ни приемник фибулы не сохранились, что существенно затрудняет типологическое определение изделия. Однако об их первоначальной форме можно судить по фотографии, представленной в отчете о полевых исследованиях могильника [Гудкова и др., 1978, табл. 67,10], на которой застежка изображена еще до очистки от патины и реставрации, частично укрытая остатками ткани (рис. 2,5). На фотографии хорошо заметна ровная прямая ножка со свободным концом, загнутым вверх под острым углом. И хотя эта деталь в месте соединения с корпусом уже надломана и смещена со своего первоначального положения, достаточно отчетливо видно, что ее конец закруглен, не доходит до края спинки и не соединен с дополнительной пластиной, припаянной к корпусу. На этом же фото присутствует и отпавшая от ножки часть с приемным аппаратом. Этот элемент представляет собой отогнутый от края ножки выступ-язычок, что необычно для гладких фибул среднелатенской схемы, имеющих, как правило, приемник-«лодочку», зато весьма характерно для тех же фибул раннелатенской схемы и отдельных форм среднелатенских «расчлененных», для которых типичен низкий прямоугольный в плане корпус с уплощенным сечением спинки.

Указанные признаки явно противоречат интерпретации рассматриваемого образца как гладкой скрепленной фибулы среднелатенской схемы. Напротив, такие отличительные черты, как низкий прямой корпус, прямоугольное сечение спинки, восьмивитковая пружина с верхней тетивой, не закрепленный на корпусе свободный конец ножки, приемник в виде язычка-выступа и т. д., сближают рассматриваемую фибулу с наиболее поздними формами застежек раннелатенской схемы, хорошо известными по находкам в позднеэллинистических захоронениях Ольвии и позднескифских склепах-катакомбах из Центрального и Северо-Западного Крыма (рис. 2,7-9) [Фурманська, 1953, с. 78, табл. I,5-10; Амброз, 1966 , с. 21 , табл. 1,12 ; Михлин, 1980 , с. $195-$ 197 , рис. 1,1-8; Храпунов, Мульд, 2004, с. 255 , рис. 12,4 ; Кропотов, 2010 , с. 38 , рис. $17,1-3]$. Погребальный инвентарь этих захоронений 
позволяет датировать данные изделия в пределах II в. до н.э., предположительно - второй половиной столетия [Кропотов, 2010, с. 38 39]. По-видимому, к этому же временному промежутку следует относить и фибулу из погребения 4 могильника Холмское.

Особого внимания заслуживает любопытная особенность рассмотренной фибулы, а именно - наличие накладной пластины на ее корпусе. Схожий элемент был встречен лишь однажды - на аналогичном, к сожалению так же сильно фрагментированном, образце из склепа 34 Беляусского могильника [Михлин, 1980, рис. 1,6; Дашевская, 2014, табл. 20,16]. На других застежках подобная черта не отмечена - дужки абсолютно всех фибул одночастные. В этой связи аргументированно обосновать функциональное предназначение указанного элемента не представляется возможным, однако с высокой долей вероятности можно предположить, что его появление связано с ремонтом изделия.

Как известно, из-за постоянной механической нагрузки многие части фибулы быстро изнашивались и приходили в негодность. Чаще других повреждения получали пружина и игла. Следы их ремонта заметны на многих застежках, в частности на идентичных образцах из склепа 17 Беляусского могильника и катакомбы 18 могильника Левадки (рис. 2,9) [Михлин, 1980, рис. 8,7; Дашевская, 2014, табл. 43,7; Храпунов, Мульд, 2004, рис. 12,4]. Оба украшения были поломаны в месте перехода пружины в иглу. Чтобы продлить срок их службы, древний мастер из отдельного куска железной проволоки изготовил новую иглу, которую свободным концом закрепил на головке фибулы [Кропотов, 2012, с. 87-88]. 3астежка из погребения 4 могильника Холмское, по-видимому, получила повреждение в месте соединения корпуса с ножкой. Чтобы как можно прочнее скрепить распавшиеся части, мастер выковал для фибулы дополнительную деталь - накладную пластину, с помощью которой надежно соединил между собой корпус и ножку изделия. Новый конструктивный элемент принял на себя всю механическую нагрузку, позволив использовать образец и в дальнейшем.

И хотя на данный момент отсутствие близких аналогий не позволяет подкрепить высказанное предположение конкретным примером, не исключено, что в будущем с увеличением числа находок появятся новые образцы, не только подтверждающие, но и дополняющие предложенную трактовку.

Не менее дискуссионной является проблема датировки фибулы из погребения 7 в кургане 1 у с. Никольское. Застежка сохранилась хорошо: она проволочная, одночленная, имеет среднелатенскую конструкцию. Свободный конец ее ножки загнут вверх, закручен в пятивитковую спираль, растянутую вдоль спинки, и завязан на головке фибулы. Пружинный аппарат - восьмивитковый с внешней тетивой, приемник - односторонний, в виде лодочки (рис. 3,3). Многочисленные аналогии среди кельтских фибул периода Латен С1 позволили исследователям отнести образец к достаточно раннему времени. Так, М.Б. Щукин датировал его последней четвертью III первой половиной II в. до н.э. [Щукин, 1989а, с. 33], В.И. Гросу - второй половиной III началом II в. до н.э. [Grosu, 1995, p. 167], А.Г. Левинский и С.М. Агульников - II в. до н.э., скорее всего серединой этого столетия [Levinschi, Agulnicov, 1998, p. 89-91]. При этом точка зрения двух последних авторов объяснялась не столько поздним временем бытования привлеченных ими аналогий, сколько желанием «подтянуть» дату всего комплекса к датировкам остальных сарматских памятников региона, отнесенных к первым векам н.э., чтобы свести к минимуму разделяющий их временной промежуток [Levinschi, Agulnicov, 1998, p. 89].

Здесь следует отметить, что достаточно близкий аналог рассматриваемого образца происходит из погребения 2 кургана 33 некрополя у с. Глиное, расположенного всего в 20 км к югу от с. Никольское [Тельнов и др., 2016 , с. 232 , рис. 117,8$]$. Эта застежка также имеет среднелатенскую конструкцию, украшена аналогичной проволочной спиралью, являющейся продолжением ножки, но отличается более широкой пластинчатой спинкой и иной формой приемника, имеющего вид язычка-выступа, ножка дополнительно украшена ложной пружиной (рис. 4,1). Эта находка датируется второй - третьей четвертями III в. до н.э. на основе наличия в комплексе с ней гераклейской амфоры, бронзовых трехлопастных втуль- 
чатых наконечников стрел, глазчатых бус и пр. [Тельнов и др., 2016, с. 955-956].

Более близкий в типологическом плане образец - проволочная фибула с идентичным по форме приемником и спиральным украшением на спинке, имеющая лишь несколько большие размеры (рис. 4,2), - известен в склепе 50 Беляусского могильника [Дашевская, 2014 , с. 34, табл. 78,8]. Надежно датированных находок вместе с ним встречено не было. Б.Ю. Михлин отнес застежку ко второй половине II в. до н.э., опираясь только на хронологические разработки Я. Филипа [Михлин, 1980, c. 209]. Последние ныне заметно откорректированы: К.В. Каспарова, М.Б. Щукин, В.Е. Еременко и другие исследователи датируют подобные украшения в основном в пределах конца III - первой половины II в. до н.э. [Каспарова, 1993, с. 170 и сл.; Щукин, 1994, с. 50-51; Еременко, Щукин, 1998, с. 70]. В соответствии с их построениями беляусскую фибулу также необходимо отнести к более раннему периоду, однако материалы, которые могли бы безоговорочно подтвердить такое уточнение, на Беляусском могильнике отсутствуют. В этой связи застежку из Беляуса, типологически, несомненно, более позднюю, чем образец из Глиного, в настоящее время следует осторожно датировать II в. до н.э., никак не сужая этот временной интервал без дополнительных уточняющих материалов.

В свою очередь, фибула из погребения 7 кургана 1 у с. Никольское по своим конструктивным особенностям, безусловно, располагается хронологически ближе к застежке из Беляуса, чем к образцу из Глиного, а потому ее также следует датировать скорее II в. до н.э., чем второй половиной или концом предшествующего столетия.

Важно подчеркнуть, что вне зависимости от того, какие именно узкие датировки для обеих рассмотренных фибул мы предложим, они, несомненно, останутся более ранними по сравнению с основным массивом фибул из раннесарматских памятников Северного Причерноморья, представленных более поздними типами - гладкими проволочными застежками среднелатенской схемы, ранними формами лучковых подвязных фибул, так называемыми воинскими и др. [Кропотов, 2016, с. 103-105]. А поскольку последние маркируют наиболее древние сарматские памятники региона, комплексы из Холмского и Никольского, в случае их сарматской атрибуции, оказываются самыми ранними не только в Поднестровье - Подунавье, но и во всем Северном Причерноморье в целом. Синхронные им бесспорно сарматские древности известны лишь в волгодонских степях и далее к востоку, на удалении не менее чем в тысячу километров (!).

В этой связи погребение 4 из могильника Холмское и погребение 7 из кургана 1 у с. Никольское логичнее соотнести с синхронными и территориально близкими им памятниками Тираспольской группы, для которых характерны сходные черты погребального обряда, в частности: положение усопшего вытянуто на спине, его меридианальная (в том числе южная) ориентировка, подстилка из растительного материала и пр. (см., например: [Тельнов и др., 2016, с. 764, 772]). При этом отсутствие в Никольском типичной для Тираспольских курганов могилы камерного типа не должно смущать, так как тип погребального сооружения этого захоронения остался неизвестным. Могила погребения 4 из некрополя Холмское своей трапециевидной формой, значительной глубиной и наличием «заплечиков» очень напоминает входные ямы катакомб III типа, наиболее характерные для Тираспольских памятников [Тельнов и др., 2016, с. 676683]. В этой связи нельзя исключать, что данное сооружение также начинали строить как катакомбу, однако строительство по какой-то причине не довели до конца, и захоронение в итоге осуществили на дне незавершенного погребального сооружения, получившего внешнее сходство с «заплечиковой» могилой.

Таким образом, подробный типолого-хронологический анализ металлических застежек-фибул из погребения 4 грунтового могильника Холмское и погребения 7 кургана 1 у с. Никольское позволил не только уточнить существующие датировки этих комплексов, наметив их в пределах II в. до н.э., но и поставить вопрос об иной их культурной атрибуции. По всей видимости, данные захоронения следует исключить из списка ранних сарматских памятников Северо-Западного Причерноморья и отнести к кругу древностей Тираспольской группы, обоснованно связываемой с позднескифской культурой. 


\section{ИЛЛЮСТРАЦИИ}

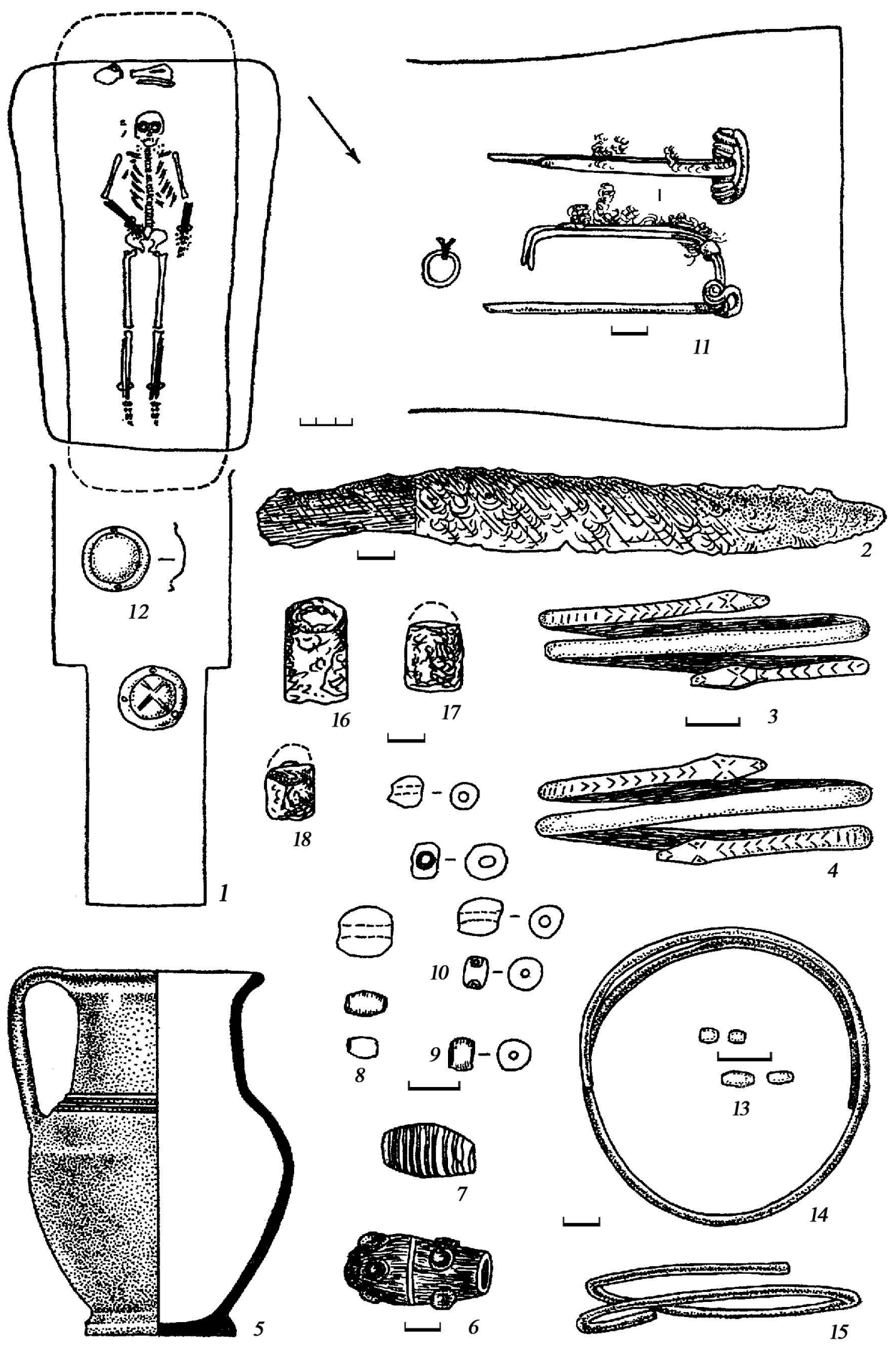

Рис. 1. План и инвентарь погребения 4 могильника Холмское (по: [Гудкова, Фокеев, 1984, рис. 2])

Fig. 1. The plan and grave goods of burial 4 from Kholmskoe cemetery (after: [Gudkova, Fokeev, 1984, fig. 2]) 
В.В. Кропотов. Две фибулы из «раннесарматских» погребений Северо-Западного Причерноморья
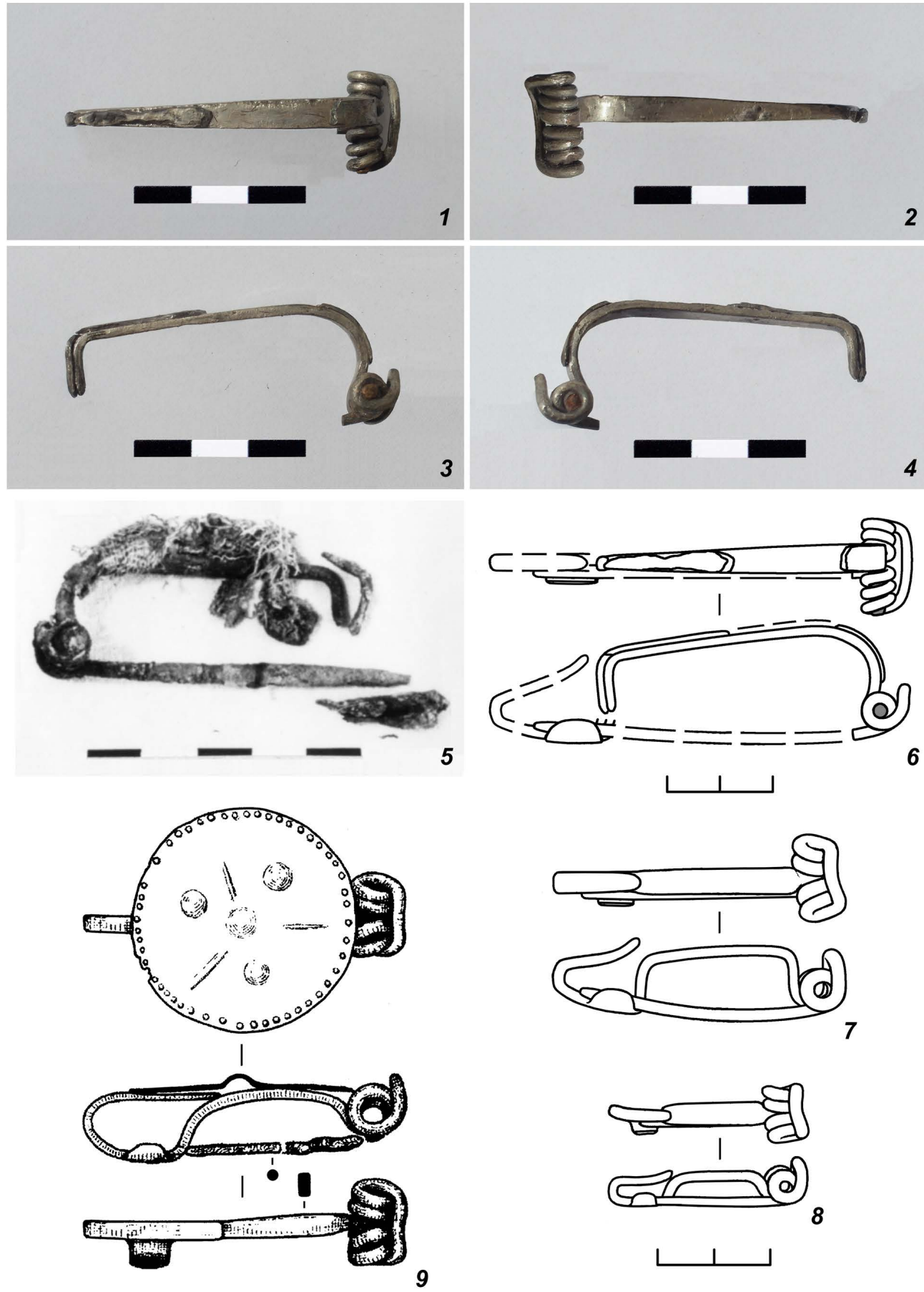

Рис. 2. Фибулы раннелатенской схемы из погребальных памятников Северного Причерноморья:

1-4 - погребение 4 могильника Холмское (фото Д.А. Масюты);

5 - погребение 4 могильника Холмское (по: [Гудкова и др., 1978, табл. 67,10]);

6 - погребение 4 могильника Холмское (реконструкция В.В. Кропотова);

7, 8 - склеп 1 Беляусского могильника (по: [Кропотов, 2010, рис. 17,1-2]);

9 - катакомба 18 Левадковского могильника (по: [Храпунов, Мульд, 2004, рис. 12,4])

Fig. 2. Fibulae of Early-Laten scheme from funeral monuments at North Pontic Region:

1-4 - burial 4 from Kholmskoe cemetery (photo by D.A. Masiuta);

5 - burial 4 from Kholmskoe cemetery (after: [Gudkova et al., 1978, taf. 67,10]);

6 - burial 4 from Kholmskoe cemetery (reconstruction by V.V. Kropotov);

7,8 - crypt 1 from Belyaus cemetery (after: [Kropotov, 2010, fig. 17,1-2]);

9 - catacomb 18 from Levadki cemetery (after: [Khrapunov, Muld, 2004, fig. 12,4]) 

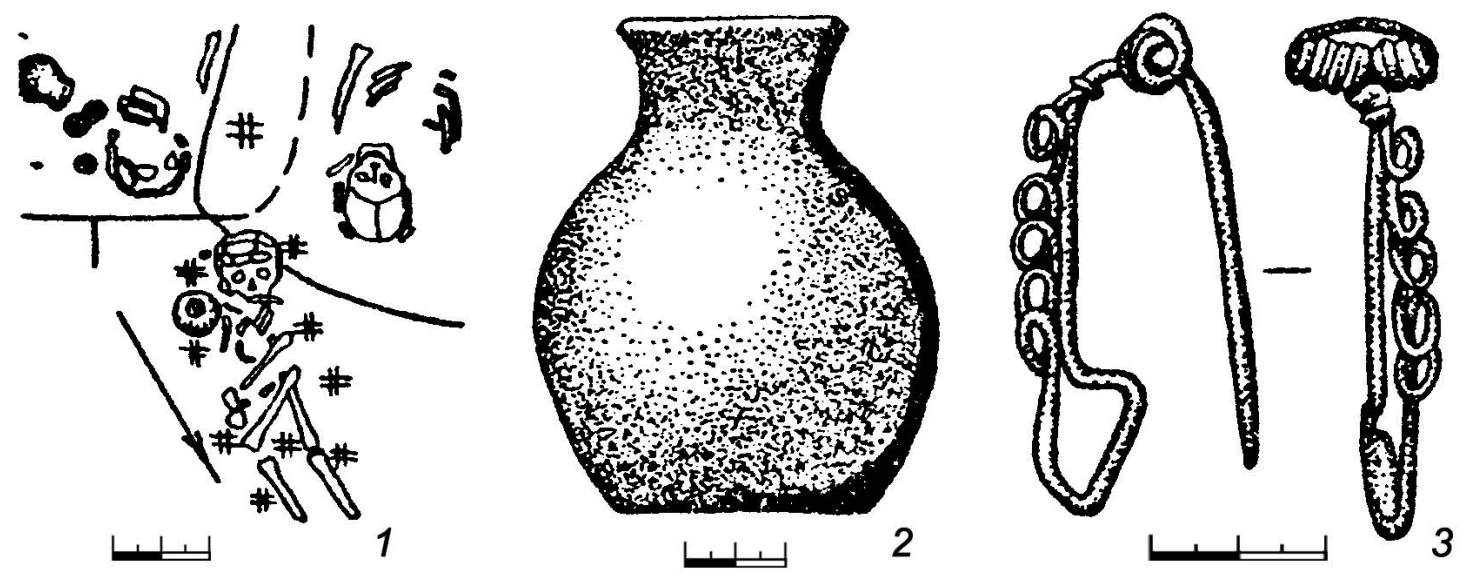

Рис. 3. План и инвентарь погребения 7 из кургана 1 у с. Никольское (по: [Levinschi, Agulnicov, 1998, fig. 1]): 1 - план погребения, 2 - лепной сосуд, 3 - бронзовая фибула

Fig. 3. The plan and grave goods of burial 7 from kurgan 1 near Nikolskoe village (after: [Levinschi, Agulnicov, 1998, fig. 1]):

1 - plan of burial; 2 - hand-made vessel; 3 - bronze fibulae
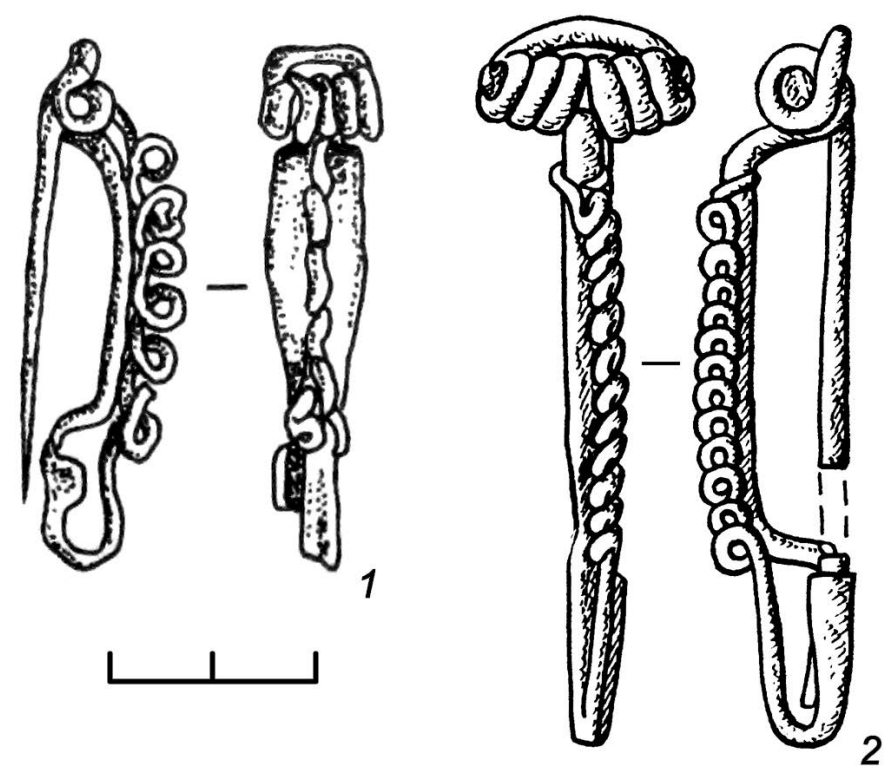

Рис. 4. Фибулы среднелатенской схемы со спиралевидными украшениями:

1 - погребение 2 из кургана 33 у с. Глиное (по: [Тельнов и др., 2016, рис. 117,8]);

2 - склеп 50 Беляусского могильника (по: [Дашевская, 2014, табл. 78,8])

Fig. 4. Fibulae of Middle-Laten scheme with spiral decoration:

1 - burial 2 from kurgan 33 near Glinoe village (after: [Telnov et al., 2016, fig. 117,8]);

2 - crypt 50 from Belyaus cemetery (after: [Dashevskaya, 2014, taf. 78,8]) 


\section{СПИСОК ЛИТЕРАТУРЫ}

Агульников С., Сава Е., 2004. Исследование курганов на левобережье Днестра. Кишинэу : CEP USM. 243 р.

Амброз А. К., 1966. Фибулы юга Европейской части СCCP II в. до н.э. - IV в. н.э. Свод археологических источников. Д1-30. М. : Наука. 150 с.

Гросу В. И., 1990. Хронология памятников сарматской культуры Днестровско-Прутского междуречья. Кишинев : Штиинца. 204 с.

Гудкова А. В., Алексеева И. Л., Тощев Г. Н., Фокеев М. М., Черняков И. Т., 1978. Отчет о работе Измаильской новостроечной экспедиции ИА АН УССР в 1978 г. // Научный архив ИА НАНУ. Д. 8746 (1978/15). 139 с.

Гудкова А. В., Фокеев М. М., 1984. Земледельцы и кочевники в низовьях Дуная I-IV вв. н.э. Киев : Наукова думка. 120 с.

Дашевская О. Д., 2014. Беляусский могильник. Симферополь : ЧП «Предприятие Феникс». 284 с.

Дзиговський О. М., 1993. Сармати на заході степового Причорномор'я наприкінці I ст. до н.е. - першій половині IV ст. н.е. Київ : Інститут археології АН України. 204 с.

Дзиговский А. Н., 2003. Очерки истории сарматов Карпато-Днепровских земель. Одесса : Гермес. 240 с.

Еременко В. Е., Щукин М. Б., 1998. К вопросу о хронологии восточного Латена и позднего предримского времени // Археологический сборник Государственного Эрмитажа. Вып. 33. С. 61-89.

Каспарова К. В., 1993. О времени возникновения зарубинецкой культуры // Археологические вести. № 2. С. 169-190.

Кропотов В. В., 2001. Погребение с фибулой среднелатенской схемы из могильника Нейзац // Бахчисарайский историко-археологический сборник. Вып. 2. С. 182-189.

Кропотов В. В., 2010. Фибулы сарматской эпохи. Киев : АДЕФ-Украина. 384 с.

Кропотов В. В., 2012. О ремонте северопричерноморских фибул в сарматское время // Музейні читання. Матеріали наукової конференії «Ювелірне мистецтво-погляд крізь віки» (Київ, 14-16 листопада 2011 г.). Київ. С. 87-92.

Кропотов В. В., 2016. Фибулы второй половины / конца II в. до н.э. - первой половины І в. н.э. из сарматских погребений Северного Причерноморья // Проблемы археологии Нижнего Поволжья : материалы V Междунар. Нижневолж. археол. конф. Элиста : Изд-во КалмГУ. С. 103-107.

Михлин Б. Ю., 1980. Фибулы Беляусского могильника // Советская археология. № 3. С. 194-213.

Сергацков И. В., 2007. Фибулы из погребений Азиатской Сарматии I - первой половины II вв. н.э. // Северный Кавказ и мир кочевников в раннем железном веке. М. : ТАУС. С. 408-431.

Симоненко О. В., 1994. Ранньосарматський період у Північному Причорномор’ї // Археологія. № 1. С. $32-48$.

Тельнов Н. П., Четвериков И. А., Синика В. С., 2016. Скифский могильник III-II вв. до н.э. у с. Глиное. Тирасполь : Stratum plus. $1096 \mathrm{c}$.

Фурманська А. І., 1953. Фібули з розкопок Ольвії // Археологія. Т. VIII. С. 76-94.

Храпунов И. Н., Мульд С. А., 2004. Катакомбы из могильников Фонтаны и Левадки в связи с происхождением позднескифской культуры // Проблемы истории, филологии, культуры. Вып. XIV. С. 239-269.

Щукин М. Б., 1989а. На западных границах Сарматии (некоторые проблемы и задачи исследования) // Кочевники евразийских степей и античный мир (проблемы контактов) : материалы 2-го археологического семинара. Новочеркасск. С. 31-56.

Щукин М. Б., 1989б. Сарматы на землях к западу от Днепра и некоторые события І в. н.э. в Центральной и Восточной Европе // Советская археология. № 1. С. 70-83.

Щукин М. Б., 1994. На рубеже эр. Санкт-Петербург : Фарн. 324 с.

Grosu V., 1995. Sarmații în spațiul geto-dacic răsăritean // Arheologia Moldovei. T. XVIII. P. 130-187.

Levinschi A., Agulnicov S., 1998. Complexe sarmatice timpurii în tumulii Nistrului de Jos // Tyragetia. T. VI/VII. P. 87-93.

\section{REFERENCES}

Agulnikov S., Sava E., 2004. Issledovanie kurganov na levoberezh'e Dnestra [Exploration of Kurgans on the Left Bank of the Dniester]. Kishineu, CEP USM. 243 p. 
Ambroz A.K., 1966. Fibuly iuga Evropeiskoi chasti SSSR II v. do n.e. - IV v. n.e. [Brooches of the South of European Part of USSR of $2^{\text {nd }}$ cent. BC $-4^{\text {th }}$ cent. AD]. Svod arkheologicheskikh istochnikov, Д1-30. Moscow, Nauka Publ. 150 p.

Grosu V.I., 1990. Khronologia pamyatnikov sarmatskoy kultury Dnestro-Prutskogo mezdurechiya [Chronology of Monuments of the Sarmatian Culture of the Dniester-Prut Interfluve]. Kishinev, Shtiintsa Publ. 204 p.

Gudkova A.V., Alekseeva I.L., Toshchev G.N., Fokeev M.M., Chernyakov I.T., 1978. Otchet o rabote Izmailskoy novostroechnoy ekspeditsii IA AN USSR v 1978 g. [The Report on the Work of the Izmail Archaeological Expedition of IAAS USSR in 1978]. Nauchnyy arkhiv IA NANU, Д. 8746 (1978/15). 139 p.

Gudkova A.V., Fokeev M.M., 1984. Zemledeltsy i kochevniki v nizoviyakh Dunaya I-IV vv. n.e. [Farmers and Nomads in the Lower Danube in $1^{\text {st }}-4^{\text {th }}$ cent. AD]. Kiev, Naukova dumka Publ. 120 p.

Dashevskaya O.D., 2014. Belyausskij mogilnik [The Belyaus Cemetery]. Simferopol, ChP "Predpriyatie Feniks" Publ. 284 p.

Dzigovskiy O.M., 1993. Sarmaty na zakhodi stepovogo Prichornomoriya naprykintsi I st. do n.e. - pershiy polovyni IV st. n.e. [The Sarmatians in the West of North Pontic Region Steppe at the End of $1^{\text {st }}$ cent. BC - first half of $4^{\text {th }}$ cent. AD]. Kiev, IA ASU. 204 p.

Dzigovskiy A.N., 2003. Ocherki istorii sarmatov Karpato-Dneprovskikh zemel [Essays on the History of the Sarmatians in the Carpathian-Dnieper Lands]. Odessa, Germes Publ. 240 p.

Eremenko V.E., Shchukin M.B., 1998. K voprosu o khronologii vostochnogo Latena i pozdnego predrimskogo vremeni [To the Question of Chronology of the Eastern Laten and Late Pre-Roman Time]. Arkheologicheskij sbornik Gosudarstvennogo Ermitazha [Archaeological Papers of the State Hermitage], vol. 33, pp. 61-89.

Kasparova K.V., 1993. O vremeni vozniknovenia zarubinetskoy kultury [About the Time of the Emergence of the Zarubintskaya Culture]. Arkheologicheskie vesti [Archaeological News], no. 2, pp. 169-190.

Kropotov V.V., 2001. Pogrebeniye s fibuloy srednelatenskoy skhemy iz mogilnika Neyzats [The Burial with a Brooch of the Middle-Laten Scheme from the Neizats Cemetery]. Bakhchisarayskiy istoriko-arkheologicheskiy sbornik [Bakhchisaray Historical and Archaeological Collected Works], vol. 2, pp. 182-189.

Kropotov V.V., 2010. Fibuly sarmatskoi epokhi [Brooches of the Sarmatian Age]. Kiev, ADEF-Ukraina Publ. 384 p.

Kropotov V.V., 2012. O remonte severoprichernomorskikh fibul v sarmatskoe vremia [About the Repair of the North Pontic Brooches in the Sarmatian Time]. Museyni chitannya. Materialy naukovoi konferentsii «Yuvelirne mistetstvo - poglyad kriz viky» (Kuyv, 14-16 lystopada 2011 g.) [The Museum Readings. The Materials of Scientific Conference "Jewelry Art - Look Through the Ages” (Kiev, 14-16 november 2011)]. Kiev, pp. 87-92.

Kropotov V.V., 2016. Fibuly vtoroj poloviny/kontsa II v. do n.e. - pervoj poloviny I v. n.e. iz sarmatskikh pogrebenij Severnogo Prichernomor'ya [Brooches of the Second Half / End of $2^{\text {nd }}$ Cent. BC - First Half of $1^{\text {st }}$ Cent. AD from the Sarmatian Burial of North Pontic Region]. Problemy arkheologii Nizhnego Povolzh'ya. Materialy $V$ Mezhdunarodnoj Nizhnevolzhskoj arkheologicheskoj konferentsii [The Problems of Archaeology of Lower Volga Region. Materials of the $5^{\text {th }}$ International Lower Volga Archaeological Conference]. Elista, KalmGU, pp. 103-107.

Mikhlin B.Yu., 1980. Fibuly Belyausskogo mogilnika [Brooches of the Belyaus cemetery]. Sovetskaya arkheologia [Soviet Archaeology], no. 3, pp. 194-213.

Sergatskov I.V., 2007. Fibuly iz pogrebehiy Aziatskoy Sarmatii I - pervoy poloviny II vv. n.e. [Brooches from the Burials of the Asian Sarmatia of $1^{\text {st }}$ - First Half of $2^{\text {nd }}$ Cent. AD]. Severnyy Kavkaz i mir kochevnikov v rannem zheleznom veke [North Caucasus and the World of Nomads in the Early Iron Age]. Moscow, TAUS Publ., pp. 408-431.

Simonenko O.V., 1994. Rann'osarmatskiy period u Pivnichnomu Prychornomorii [The Early Sarmatian Period in the North Pontic Region]. Arkheologiya [Archaeology], no. 1, pp. 32-48.

Telnov N.P., Chetverikov I.A., Sinika V.S., 2016. Skifskiy mogilnik III-II vv. do n.e. u s. Glinoe [Scythian Cemetery of $3^{\text {rd }}-2^{\text {nd }}$ Cent. BC Near Glinoe Village]. Tiraspol, Stratum plus Publ. 1096 p.

Furmanska A.I., 1953. Fibuly z rozkopok Olvii [Brooches from the Excavations of Olbia]. Arkheologiya [Archaeology], vol. VIII, pp. 76-94.

Khrapunov I.N., Muld S.A., 2004. Katakomby iz mogilnikov Fontany i Levadki v svyazi s proiskhozhdeniem pozdneskifskoy kultury [Catacombs from the Cemeteries of Fontany and Levadki in Connection with the Origin the Late Scythian Culture]. Problemy istorii, filologii, kultury [Journal of Historical, Philological and Cultural Studies], vol. XIV, pp. 239-269. 
B.B. Кропотов. Две фибулы из «раннесарматских» погребений Северо-Западного Причерноморья

Shchukin M.B., 1989a. Na zapadnykh granitsakh Sarmatii (nekotorye problemy i zadachi issledovaniya) [On the Western Borders of Sarmatia (Some Problems and Task of Research)]. Kochevniki evraziyskikh stepey $i$ antichnyy mir (problemy kontaktov). Materialy 2-go arkheologicheskogo seminara [The Nomads of the Eurasian Steppes and Ancient World (Contact Problems). Materials of $2^{\text {nd }}$ Archaeological Workshop]. Novocherkassk, pp. 31-56.

Shchukin M.B., 1989b. Sarmaty na zemlyakh k zapadu ot Dnepra i nekotorye sobytiya I v. n.e. v Tsentralnoy $\mathrm{i}$ Vostochnoy Evrope [The Sarmatians in the Lands West of the Dnieper and Some Events of $1{ }^{\text {st }}$ Cent. AD in Central and Eastern Europe]. Sovetskaya arkheologia [Soviet Archaeology], no. 1, pp. 70-83.

Shchukin M.B., 1994. Na rubezhe er [On the Turn of Erae]. Saint-Petersburg, Farn Publ. 324 p.

Grosu V., 1995. Sarmații în spaţiul geto-dacic răsăritean [The Sarmatians in eastern Geto-Dacian space]. Arheologia Moldovei [Archaeology of Moldova], vol. XVIII, pp. 130-187.

Levinschi A., Agulnicov S., 1998. Complexe sarmatice timpurii în tumulii Nistrului de Jos [The Early Sarmatian complexes of the Lower Nistru kurgans]. Tyragetia [Tyragetia], vol. VI/VII, pp. 87-93.

\section{Information About the Author}

Viktor V. Kropotov, Candidate of Science (History), Senior Researcher, Institute of Archaeology of the Crimea (RAS), Prosp. Vernadskogo, 2, 295053 Simferopol, Russian Federation, v-kropotov@bk.ru, https://orcid.org/0000-0001-8317-0272

\section{Информация об авторе}

Виктор Валерьевич Кропотов, кандидат исторических наук, старший научный сотрудник, Институт археологии Крыма РАН, просп. Вернадского, 2, 295053 г. Симферополь, Российская Федерация, v-kropotov@bk.ru, https://orcid.org/0000-0001-8317-0272 